\title{
Los jóvenes lectores de la derecha argentina. Un acercamiento etnográfico a los seguidores de Agustín Laje y Nicolás Márquez
}

Analía Goldentul ${ }^{(1)}$ y Ezequiel Saferstein ${ }^{(2)}$

\begin{abstract}
Resumen: Este artículo aborda la relación entre edición y política a partir del estudio de la producción, circulación y recepción de autores y libros circunscriptos a la ideología de derechas. Recientemente, los autores Nicolás Márquez y Agustín Laje, publicados por la editorial de derechas Unión, han logrado una visibilidad inusitada, reflejada en la circulación y venta de sus libros y la masividad de los eventos y presentaciones. Argumentamos que el circuito de comunicación que produce y reproduce sus discursos tiene a los libros como objetos que se difunden y permiten que sus autores se conviertan en referentes intelectuales, culturales y políticos con "autoridad" y que crean comunidades de lectores. Éstos compran, leen y los utilizan como fundamento y como modo de asegurar sus creencias, sentimientos y opiniones políticas. A partir de entrevistas y seguimiento del público de estos autores exploramos las formas de sociabilidad y de subjetivación política que estos autores y sus libros habilitan en un espacio de circulación de ideas de derechas en la Argentina actual.
\end{abstract}

Palabras clave: Derechas - etnografía - intelectuales - edición y política - cultura política - editoriales - lectores.

[Resúmenes en inglés y portugués en las páginas 130-131]

(1) Analía Goldentul es socióloga, magister en Estudios Sociales Latinoamericanos por la Facultad de Ciencias Sociales de la UBA y becaria doctoral de CONICET bajo la dirección de Verónica Giordano. Sus líneas de investigación son derechas, dictadura y derechos humanos. Se enfoca particularmente en las formas de activismo de familiares de militares, policías y civiles condenados por crímenes de lesa humanidad, atendiendo sus narrativas, emociones, consumos culturales y repertorios de acción.

(2) Ezequiel Saferstein es sociólogo, magister en Sociología de la Cultura por el Instituto de Altos Estudios Sociales y doctor en Ciencias Sociales por la Facultad de Ciencias Sociales (UBA). Es investigador del CONICET con sede en el Centro de Documentación e Investigación de la Cultura de Izquierdas (CeDInCI/UNSAM). Sus líneas de investigación están vinculadas a los estudios de edición y política desde una perspectiva sociológica de la cultura. Se enfoca particularmente en la producción de libros de política desde la perspectiva de sus autores y editores y sus modalidades de intervención pública. 


\section{Introducción}

Este artículo propone abordar la relación entre libros y cultura política a partir del análisis de la producción, circulación y difusión de libros de política argentina reciente, circunscriptos a la ideología de derecha ${ }^{1}$. En los últimos años, diferentes actores políticos, académicos, intelectuales y mediáticos intervienen en la producción de visiones acerca de, entre otras cuestiones, la política nacional, las relaciones de género y la interpretación de la represión militar y del pasado reciente, a través de libros, notas, programas de televisión, artículos, intervenciones en las redes sociales y eventos. Los autores Nicolás Márquez y Agustín Laje han logrado una visibilidad inusitada, reflejada en la circulación y venta de sus libros -particularmente El libro negro de la nueva izquierda (2016) - y la masividad de los eventos y presentaciones.

Este best seller, publicado por el pequeño sello editorial Unión, lleva vendidos 20.000 ejemplares y se orienta al combate contra el "marxismo cultural" y la "ideología de género". Sus autores se encuentran amparados por espacios de producción cultural (editoriales y redes sociales), así como por instituciones trasnacionales (fundaciones y think tanks liberales), que garantizan su circulación. Laje y Márquez han emprendido exitosas giras por Argentina, México, Paraguay, Costa Rica, República Dominicana Perú y España, entre otros países, que les permitieron difundir sus ideas y libros a nivel internacional y adquirir visibilidad mediática.

Consideramos que el circuito de comunicación que produce y reproduce sus discursos (editorial, intermediarios, otros pares y referentes, lectores y público) tiene a los libros como objetos que se difunden y permiten que sus autores se conviertan en referentes intelectuales, culturales y políticos con "autoridad" (Saferstein, 2016). Pero, además, crean y fortalecen comunidades de lectores, que los compran, los leen, los utilizan como fundamento y como modo de asegurar sus creencias, sentimientos y opiniones políticas (Semán, 2006). A partir de una serie de observaciones no participantes en eventos de presentación de libros y de entrevistas al público seguidor de estos autores, se busca explorar la relación entre libros y cultura política de derecha en la Argentina actual.

Mientras el vínculo entre los impresos y cultura de izquierdas ha sido largamente estudiado (Tarcus, 2013; Sorá, 2017; Mollier y Midori Daecto, 2013), su convergencia con espacios de sociabilidad de derecha conforma hasta hoy en día un área de vacancia, pese al valor que los propios actores que participan de estos círculos les asignan a los impresos. En Argentina las derechas han sido estudiadas en términos ideológicos y doctrinarios (Besoky, 2016; Vicente, 2015; Morresi, 2010), en clave comparada (McGee Deutsch, 2005; Bohoslavsky y Lvovich, 2009) y en sus formas de organización colectiva (Gomes, Bohoslavsky y Broquetas, 2018). En diálogo con estos trabajos de corte historiográfico abocados en su mayoría al siglo XX, en los últimos años ha emergido una literatura que hace foco en las "nuevas derechas" desde abordajes sociológicos y antropológicos (Soler, Giordano y Saferstein, 2018). Estos estudios se centran en los circuitos educativos de la clase alta (Gessaghi, 2016), en los perfiles empresariales de los funcionarios (Canelo y Castellani, 2016), en las vías de reclutamiento de managers por parte de las alianzas que le permiten llegar al poder político (Vommaro, 2017) y en las formas de militancia juvenil (Grandinetti, 2019; Kessler y Vommaro, 2019; Vázquez, Rocca Rivarola y Cozachcow, 2016). 
Por tratarse de un fenómeno reciente, es posible identificar un área de vacancia en relación con la formación de espacios de derecha que no se sienten identificados con la coalición de partidos que gobernó en Argentina entre 2015 y 2019, PRO, UCR y Coalición Cívica. Si bien los sectores vinculados a los intelectuales sobre los que trabajamos tienen escasa competencia electoral ${ }^{2}$ su configuración está a tono con el crecimiento de las "sensibilidades autoritarias" (Kessler y Vommaro, 2019) a nivel regional y europeo, y con la progresiva articulación de redes transnacionales de las que participan intelectuales, expertos, think tanks y movimientos religiosos (Soler, Giordano y Saferstein, 2018; Soler y Giordano, 2016).

Tomando distancia de aquellos enfoques que ponderan a las derechas desde el punto de vista únicamente partidario, este artículo hace foco en el valor de los libros como artefactos culturales con valor simbólico que inciden en la construcción de espacios de socialización de derecha, el cual estudiamos a partir de los lectores de Agustín Laje y Nicolás Márquez. Organizado en tres apartados, el artículo explora, en primer lugar, la relación entre derecha, cultura y libros en la coyuntura actual. En segundo lugar, se abordan las presentaciones de libros como espacios fértiles para la germinación de redes, lazos sociales y la articulación de alianzas políticas. Por último, se indagan las prácticas y discursos de tres jóvenes lectores de El Libro negro de la nueva izquierda, en relación con sus incursiones en la literatura de derecha, sus cosmovisiones políticas y los lazos construidos en estos ámbitos emergentes.

\section{Libros y cultura de derechas en la coyuntura actual}

En su estudio etnográfico sobre jóvenes berlineses de "extrema derecha", Nitzan Shoshán (2017) registró que los conflictos sociales en Alemania y en Europa central tendían a dirimirse en términos culturales antes que en confrontaciones de clase. A comienzos del siglo XXI, la desindustrialización larvada comenzaba a dejar huella en el plano de las identidades, tanto de aquellas arraigadas en el consumo como de las que tenían base en la posición de clase. Como contraparte de este declive, la defensa de la nación afloró en algunos recovecos de Berlín como "un nicho de identidad". La oposición activa a la promoción oficial de la diversidad (lingüística, étnica, religiosa, política) y al "multiculturalismo neoliberal” emergió para muchos jóvenes como un catalizador de las dificultades sociales, educativas y económicas que atravesaban diariamente.

Posicionando de este modo a la cultura y sus artefactos como principal locus de confrontación en la vida cotidiana de jóvenes identificados con la extrema derecha, el trabajo de Shoshán ilumina ciertos aspectos de nuestro objeto de estudio en Argentina, donde la culturalización de los conflictos también ha teñido de formas particulares la oposición entre izquierda y derecha. Desde los últimos años referentes intelectuales, editores y políticos de la derecha vernácula eligen eventos, conversatorios y presentaciones de libros como escenarios predilectos para transmitir sus ideas ante públicos multitudinarios, compuestos por viejas y nuevas generaciones. Desde una perspectiva material vinculada a la historia intelectual y la sociología de la cultura (Darnton, 1993; Dosse, 2007; Grafton, 2007), consi- 
deramos que estos espacios son fundamentales para entender los sentidos que los lectores le asocian a los libros que leen, compran y comentan. En estos espacios de sociabilidad, la cultura gravita no solamente como soporte sino también como contenido, es decir, como sustrato de los argumentos a través de los cuales se busca encauzar, convencer y generar adhesión.

El eje de las intervenciones y de los libros parte, en efecto, de una resignificación de la idea gramsciana de "batalla cultural" para confrontar con todo aquello que es identificado con el "marxismo" (cultural) y la "ideología de género", dos elementos que son indicativos de la cultura dominante de "izquierda”. Más aún, en muchos casos el ingreso de jóvenes a estos espacios no se vio propiciado por causales económicas -si bien esta es una variable que debe ser contemplada- sino por factores de raigambre cultural, como el rechazo a la legalización del aborto: una problemática que en Argentina fue sometida a votación en el Congreso nacional entre marzo y octubre de 2018, con un resultado negativo para su sanción. En este marco, los libros aparecen como herramientas claves para dar la "batalla" con "argumentos", pero también como bienes simbólicos que ayuda a construir y ampliar el perfil de algunos referentes de derecha. Dos figuras que han cobrado relevancia y que permiten ilustrar esta tendencia son Nicolás Márquez (Mar del Plata, 1975) y Agustín Laje Arrigoni (Córdoba, 1989). Abogado por la Universidad Nacional de Mar del Plata e inscripto ideológicamente en el conservadurismo católico, Márquez publicó en 2004 su primer libro, $\mathrm{La}$ otra parte de la verdad (Edición del autor, 2004 y Contracultura, 2012), en el que plasmó su interpretación de la dictadura desde una posición revisionista que apuntó a "desvelar" verdades del pasado reciente contrarias a la interpretación "oficial" (Salvi, 2012). Este libro, junto con La mentira oficial: el setentismo como política de Estado (Edición del autor, 2006), lo convirtieron en una referencia obligada para los activistas de la "memoria completa" y para los miembros de organizaciones que reivindican los derechos de los agentes de la represión ${ }^{3}$.

Laje, por su parte, es politólogo por la Universidad Católica de Córdoba, presidente de la Fundación Libre ${ }^{4}$, autor de Los mitos setentistas: mentiras fundamentales de la década del 70 (Edición de autor, 2011 y Unión, 2012), y como el think thank que preside, se inscribe mayormente dentro de la tradición liberal. En conjunto publicaron Cuando el relato es una farsa. La respuesta a la mentira kirchnerista (Contracultura; 2013) y el libro que nos ocupa en este artículo, El libro negro de la nueva izquierda. Ideología de género o subversión cultural (Unión, 2016).

Si sus primeras ediciones estuvieron a cargo de los propios autores, pronto pasaron a ser publicados por pequeñas editoriales de derechas, como Contracultura y el Grupo Unión ${ }^{5}$. Ambos autores ingresaron en el mundo de los libros a partir de tematizar sobre el último período dictatorial. Sus obras estuvieron a tono con una tendencia más amplia que comenzó en 2003 y se profundizó en los años siguientes, signada por el interés de las grandes editoriales en los años setenta y por el éxito en la venta de libros de este género (Saferstein, 2016; 2017; Campos, 2009).

Junto al gran impacto mediático que lograron la trilogía de Juan Bautista "Tata" Yofre Fuimos todos (2006), Nadie Fue (2007) y Volver a Matar (2009) y los best sellers de Ceferino Reato, Operación Traviata (2008) y Disposición Final (2012) -todos publicados por Random House Sudamericana bajo la dirección de Pablo Avelluto- fue emergiendo un 
circuito editorial de libros sobre los setenta. Estos núcleos buscaron difundir lecturas disonantes elaborados por agentes que basaban su legitimidad autoral en el hecho de haber sido "protagonistas" en los setenta: ex militantes "arrepentidos" de su participación en organizaciones armadas (Leis, 2013; Hilb, 2013), militares retirados que participaron de la "lucha antisubversiva" (D'Angelo, 2014) y militantes de "memoria completa" (Manfroni y Villarruel, 2014), entre otros. Aunque desde ángulos distintos -en algunos casos, radicalmente distintos-, todos discutían la "memoria oficial" del kirchnerismo.

Las figuras que aquí ocupan nuestra atención y, sobre todo, el capital simbólico otorgado por mediadores referentes - prologuistas, editores, reseñistas, políticos, intelectuales-, por instancias de circulación y por su éxito editorial, conjugaron su intervención en el espacio público. En 2016, Laje y Márquez lanzaron al mercado el ya mencionado El libro negro de la nueva izquierda. Ideología de género o subversión cultural, desde la editorial Unión, prologado por el abogado de la Asociación Justicia y Concordia ${ }^{6}$, Gerardo Palacios Hardy. La obra es deudora de la literatura previamente existente en torno a los setenta pero también la excede, en tanto buscó intervenir en asuntos de coyuntura política y en campos temáticos más amplios como la cuestión de género, del aborto y las “ideologías” derivadas, como el feminismo y el "homosexualismo", en palabras de los autores (Márquez y Laje, 2016). Se compone de dos secciones: una primera parte - "Postmarxismo y feminismo radical"-, escrita por Laje; y una segunda parte -"Homosexualismo cultural"-, firmada por Márquez (Elman, 2018).

Sus páginas no sólo refrendaron a sus autores como escritores, intelectuales e influencers dentro del espacio de la ultraderecha. Con más de 20.000 ejemplares vendidos -según datos aportados por su editor- también generaron un público lector que acude a eventos y a diversas instancias de presentación del impreso para escuchar en primera persona la palabra de estos actores.

\section{Las presentaciones de libros como espacios de sociabilidad de derechas}

Así como Laje y Márquez cosechan un masivo y activo público seguidor en las redes sociales, El libro negro de la nueva izquierda se erigió como un artefacto simbólico eficaz para tender lazo social. Éste propició el encuentro físico entre los seguidores y permitió "refrescar" la cultura política de derecha ${ }^{7}$, mediante el recurso del humor y la polémica en cuanto a lo discursivo, y mediante la generación de momentos y espacios de sociabilidad concretos, como las presentaciones y conferencias.

En términos más precisos se sostiene, a modo de hipótesis, que no se trató de actualizar esta vertiente política con el libro (lo cual exigiría un análisis de contenido de la obra) sino a partir de él, capitalizando las oportunidades que este generó para multiplicar relaciones sociales y afianzar una comunidad política. Como sostiene Besoky (2016), la reproducción de las culturas políticas requiere no solo textos canónicos y bases ideológicas, sino también la "realización de prácticas reiterativas, la repetición de rituales y ceremonias y la participación en eventos y manifestaciones que sirvan para sellar compromisos de los adherentes y confirmar el sentido de pertenencia a un grupo". 
Durante el trabajo de campo de la investigación en la que se enmarca este artículo, asistimos a dos conferencias que tuvieron a Laje y Márquez como oradores destacados. La primera de ellas, "Conversación de cara a la elección 2019" tuvo lugar en diciembre de 2018 en el Club Español, y la segunda, "Nuevos ataques a la libertad" se desarrolló en marzo de 2019, en el auditorio de Belgrano, ambos en la ciudad de Buenos Aires. Mientras la actividad en el Club Español fue gratuita y tuvo una difusión y asistencia más acotadas, el evento en el barrio de Belgrano fue arancelado, replicó el formato de las conferencias TEDx, y contó con un auditorio de mil personas aproximadamente.

Estos eventos pueden ser pensados como performances rituales, en términos de Marc Abeles (1990), en donde se construye simbólicamente la política y circulan sentidos diversos a los que se puede acceder desde una perspectiva etnográfica (Semán, 2006). En estas presentaciones y conferencias, los autores se posicionan como tales, al subrayar y referir a su producción, orientar la lectura a partir de sus propias interpretaciones e interactuar con sus lectores y sus apropiaciones.

Junto con sus intervenciones en las redes sociales, el libro de Laje y Márquez funcionó como condición de posibilidad de ambos eventos, al propiciar lectores con potencialidad de ser interpelados políticamente y ser configurados como público-asistente. Justamente, en torno al libro pudo observarse un mismo ritual hacia el momento cúlmine de cada jornada: jóvenes expectantes que habían acudido a la cita con su ejemplar del libro, formaban fila para obtener la firma de los referentes. Cerca de la mesa reservada para las firmas de los autores, podía apreciarse un stand de libros organizado por el sello Unión, en el que se destacaba $E l$ libro negro... y otras obras de cuño liberal, además de artículos de librería grabados con la portada del libro y con otras imágenes irónicas hacia sectores progresistas y de izquierda.

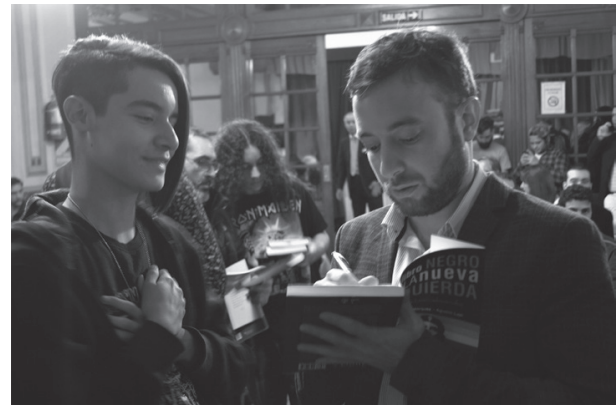

Figura 1. (izquierda) Laje firma el ejemplar de El libro negro de la nueva izquierda (Club del Progreso, CABA, 13/12/18). Fuente: Elaboración propia.

Figura 2. (derecha) Mesa de libros organizada por el sello Unión (Club del Progreso, CABA, 13/12/18). Fuente: Elaboración propia.

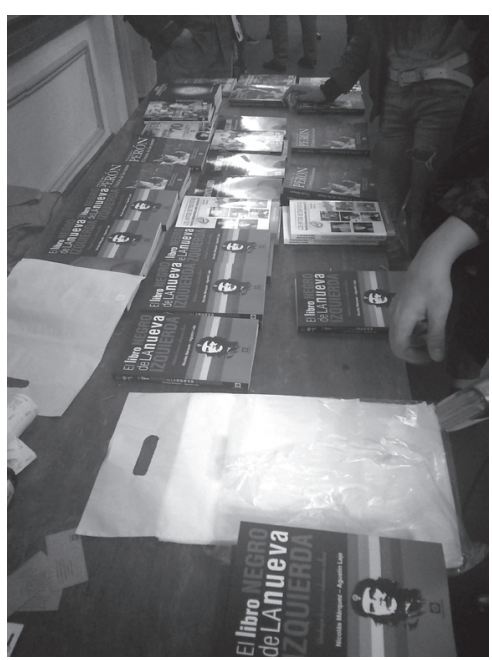



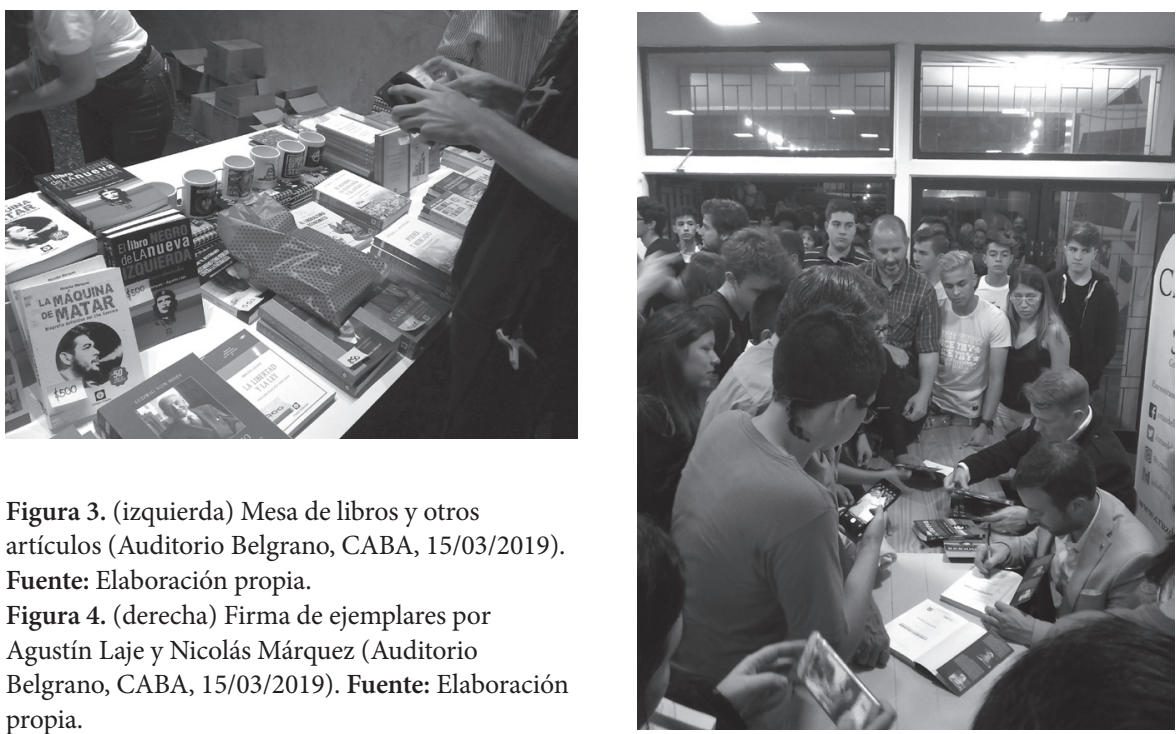

Figura 3. (izquierda) Mesa de libros y otros artículos (Auditorio Belgrano, CABA, 15/03/2019). Fuente: Elaboración propia.

Figura 4. (derecha) Firma de ejemplares por Agustín Laje y Nicolás Márquez (Auditorio Belgrano, CABA, 15/03/2019). Fuente: Elaboración propia.

Sin considerar estos espacios, con sus dinámicas, lógicas y prácticas políticas, como un resultado mecánico del fenómeno editorial, el "efecto libro" (Darnton, 1996) es aquí ponderado en su capacidad de construir figuras con "autoridad", generar entramados de relaciones sociales y, como se verá en el siguiente apartado, articular adhesiones y voluntades políticas.

\section{Jóvenes lectores y cultura de derecha}

Los seguidores y lectores de Agustín Laje y Nicolás Márquez componen un grupo social disperso que no podría ser trazado de manera homogénea en cuanto a trayectorias de clase, niveles socioeducativos o índices culturales. En la jornada del 14 de marzo de 2019 en Belgrano pudimos observar perfiles diversos en la fila que se había formado sobre la avenida Cabildo para ingresar al auditorio: jóvenes veinteañeros identificados como liberales, adolescentes fanáticos de la cultura manga y animé, con prendedores alusivos en sus morrales, jóvenes con remeras de bandas de heavy metal nacional e internacional, grupos de adolescentes católicos o cristianos identificados con el pañuelo celeste de la campaña "Salvemos las dos vidas", entre otras culturas juveniles.

Si en las redes sociales muchos de los seguidores de Agustín Laje y Nicolás Márquez se muestran agresivos ante cualquier posteo que los critique o ridiculice, en los eventos asisten contentos, entusiasmados, con ganas de conversar entre sí y conocerse, dispuestos a 
escuchar a sus referentes que "ponen en palabras" lo que ellos sentían y no sabían cómo expresar.

Con los referentes es posible percibir otra forma de contraste. Así como en sus intervenciones en redes sociales y en medios de comunicación masiva estas figuras utilizan un "lenguaje de odio", en el marco de eventos la virulencia discursiva es acompañada de una tónica prescriptiva que insta a la "tolerancia" entre las diferentes corrientes ideológicas que confluyen en el espectro de la derecha: el liberalismo, el conservadurismo y el nacionalismo. Considerando que una de las características principales de las culturas políticas es su ósmosis y permeabilidad (Besoky, 2016), en el evento en el auditorio de Belgrano Márquez manifestó tener la esperanza de ver en la Argentina "liberales que crean en la vida desde la concepción, conservadores que crean que la tradición tenga que estar al servicio del progreso y nacionalistas que no confundan el amor a la patria con el amor al Estado".

Aunque las culturas políticas pueden ser aprehendidas a partir del mapa de representaciones ideológicas que las conforman, estas también pueden estudiarse como "prácticas encarnadas en los recorridos de sus adherentes" (Besoky, 2016). En esa dirección, luego de realizar observaciones no participantes en los eventos a los que asistimos en 2018 y 2019, hacia el final de la charla en el Club Español mantuvimos conversaciones informales con una decena de jóvenes seguidores. Además, en los meses siguientes, realizamos entrevistas en profundidad, semi-estructuradas a tres de ellos: Santiago (23 años), Andrés (25 años) y Pamela (33 años). ${ }^{9}$ Cada uno de ellos se inclinó por una vertiente política en particular, aunque mostró aceptación hacia el resto de las tradiciones. En este proceso de actualización de la cultura política de derecha, los libros parecen cumplir diversas funciones: ofrecen argumentos para dar la "batalla cultural", materializan y le dan forma a pensamientos "que ya tenían" y permiten un reconocimiento entre pares. La selección de los entrevistados obedeció a criterios cualitativos delineados en función de los objetivos de la investigación. Además de ser condición la participación en espacios y eventos de la nueva alt right argentina, era prioritario que los entrevistados tuvieran vinculación con la cultura de los libros. La inclusión de perfiles de lectores diversos, si bien no agota la heterogeneidad del amplio universo joven en que se inscriben estas trayectorias, resulta productiva para establecer similitudes y contrapuntos, y robustecer el análisis.

Los jóvenes entrevistados, veremos a continuación, develan de este modo distintos vínculos y formas de apropiarse de los libros que los sustrae de la mera figura del "receptor" pasivo. Los libros permiten a los lectores involucrarse de diversas maneras, mediante prácticas que van más allá de las intenciones del autor (Canavese, 2015; Chartier, 2005; García, 2009; Tarcus, 2013). En este sentido, entendemos que no hay lecturas correctas o incorrectas de las obras, sino que en sus modos de producción, circulación y consumo se puede llegar a entender qué, cómo y por qué fue leída la obra. El texto no existe como "cosa en sí" sino que siempre es leído de maneras determinadas, contextuadas histórica y socialmente:

El texto no existe por fuera de la historia de sus interpretaciones (...). Entre el lector y el texto se interpone necesariamente toda una malla de interpretaciones previas. Cada texto ha acumulado una historia de efectos e interpretaciones que son parte constitutiva de su significado para nosotros. El texto no es sino la historia del texto, la historia de sus lecturas (Tarcus, 2013, p. 34). 


\section{Los libros para la contrarreacción}

Se ha despertado una contrarreacción. En términos de la revolución francesa, somos los contrarrevolucionarios, para frenar todo. Ha despertado gente que no se movilizó nunca en su vida. Han tocado la fibra tan íntima, valores tan arraigados, que salen a la calle porque no pueden más.

Santiago tiene 23 años y explica de esa manera el momento que vive la derecha. Sigue a Agustín Laje y a Nicolás Márquez en sus conferencias, en las redes y en sus libros. Su inclinación por la religión y las ideas de derecha parece haberse salteado una generación. Sus abuelos paternos y maternos eran militares y católicos. Sus padres, en cambio, son ateos y de izquierda. Como cuando nació sus padres eran muy jóvenes y trabajaban, Santiago pasó parte de su infancia con sus abuelos, a quienes los reconoce como los transmisores de sus creencias y adhesiones. Santiago se define como "liberal conservador" desde muy joven: "La rebeldía de mi mamá fue por izquierda. A mí siempre me gastan con que la rebeldía hacia mis padres fue por derecha".

Su ejemplar de El libro negro de la nueva izquierda está gastado por su uso, sus lecturas y sus anotaciones. Su copia pasó por las manos de un amigo que comparte sus ideas y también por las de una profesora de su facultad, a quien se lo prestó luego de una acalorada discusión en clase sobre la violencia de género: "Ella es radical, de centroizquierda. Le dije 'Llevate el libro y leelo'. Me lo devolvió marcado, se ve que lo leyó”. Cuenta que, aunque la profesora no estaba de acuerdo con lo que el libro decía, él se sentía contento con que haya podido leer los argumentos de su postura y que por lo menos le hayan hecho "ruido". Santiago sigue a Laje y a Márquez porque considera que su voz busca reunir a la toda la derecha, dejando de lado las diferencias existentes para "enfrentarse" al enemigo común en mejores condiciones. "Ellos encauzaron todo lo que yo venía haciendo por separado, todo en un mismo lugar". Sostiene sin dubitaciones que el enemigo es "el marxismo cultural":

Laje lo dice muy claro y lo explica mucho mejor que yo: es el avance contra las instituciones que sostienen el Estado: la familia, la iglesia y las FFAA. Acá en los setenta quisieron imponer un estado socialista y no les fue bien, ahora la izquierda va más por lo cultural, por lo económico (Santiago, 24 años, marzo de 2019).

Santiago tiene una pequeña biblioteca en el monoambiente que alquila en Barrio Norte de la ciudad de Buenos Aires. Allí ubica los libros que compra de manera frecuente. Aunque no haya un orden que pueda identificarse a simple vista, sobresalen dos temáticas principales. Por un lado, los libros religiosos y sobre el catolicismo: distintas ediciones de la biblia, las Confesiones de San Agustín, Historia de los Papas, Catecismo de la Iglesia Católica y La fuerza de la vocación, una entrevista con el Papa Francisco, entre muchos otros. Por otro lado, los libros que define como "de política", pero donde priman los títulos revisionistas sobre los años setenta, los que niegan el terrorismo de Estado y al mismo tiempo reivindican el accionar militar: los dos títulos de la dirigente del Centro de Estudios Legales sobre el Terrorismo y sus Víctimas (CELTYV), Victoria Villarruel Los llaman...jóvenes 
idealistas y Los otros muertos, coescrito con Carlos Manfroni y Mentirás tus muertos del ex militar José D’Angelo. También tiene Circo Kirchner de la funcionaria de Cambiemos Laura Alonso, La revolución del 55 del abogado Isidoro Ruiz Moreno y clásicos de la Ciencia Política, como La República de Platón. Sus librerías favoritas son las católicas de Barrio Norte, como San Pablo y Claretiana.

Santiago terminó la secundaria en un colegio público y decidió estudiar Ciencias Políticas en la Universidad del Salvador. Tuvo un pasaje por el Instituto Joaquín V. González, donde estudió profesorado en Ciencias Jurídicas por un año. Lo revive como una experiencia dura, entre otras cosas porque reprobó un trabajo en el cual basó su argumentación en sus libros sobre los años setenta, no inscriptos en la historiografía académica sobre el pasado reciente. En la contraposición de visiones sobre la realidad, considera a esta última como "tendenciosa" y la visión que sus libros aportan, como "fáctica". Al igual que Laje, piensa que los libros que lee aportan datos, información objetiva y por ende, incontrastable:

Yo cito autores, cito estadísticas. Los libros me dieron datos: 'Muere un hombre cada tres horas', lo dice la OMS. Te da argumentos, me ayuda a orientar mis debates, porque vos de ideas podés debatir mucho, pero a los datos no podés debatir, los muertos están en la morgue, eso es claro (Santiago, 24 años, marzo de 2019).

Su vida transita mayormente por espacios de socialización católica: va a la Facultad por la mañana y por las tardes alterna entre sus clases de catequesis, los círculos de formación del Opus Dei y la participación en las reuniones de Marcha por la Vida, una de las organizaciones que lideraron la lucha en contra del aborto en Argentina. Asiste a misa casi todos los días y antes de dormir lee la Biblia.

En cuanto a su actividad política, votó a Macri en 2015 y al momento de la entrevista se siente desilusionado. Incluso militó en el PRO, pero abandonó el partido por considerar que Cambiemos era "más de lo mismo". Fue militante, fiscal de mesa y secretario de comunicación de una comuna. Sin embargo, el tratamiento en el Congreso de la legalización del aborto fue un punto de inflexión. Lo dice de manera enfática:

Me preocupan los temas valóricos. Cuando veo esto de las casas para los transexuales, la hormonización y todo pagado con nuestros impuestos, dije basta, eso no lo negocio. En lo económico podemos diferir, negociemos, pero el tema de vida y familia no porque es la base de la sociedad, si tocas eso se viene todo abajo. Lo que quieren hacer con la educación sexual es una locura. Mis compañeros me decían 'no te vayas, pensamos como vos', pero nadie hace nada (Santiago, 24 años, marzo de 2019).

A tono con la tradición liberal argentina (Vicente, 2015), sus argumentos de la libertad económica congenian con la postura autoritaria-conservadora en el resto de los planos de la vida social: "Yo siempre tuve claro lo que era la familia, lo que era la vida, si bien no era un militante, no me lo ponía en cuestionamiento. La familia es esto y la vida es esto, no hay discusión. Ahora tenemos que explicar que la vida empieza desde la concepción, es insólito". 


\section{Lectura, escritura y praxis}

Pamela tiene 33 años, es ecuatoriana y vive en Buenos Aires desde que alcanzó la mayoría de edad. Además de ser Profesora en Lengua Inglesa (UADE), se presenta como traductora, columnista en el Panam Post, voluntaria en la Fundación Libre y cofundadora del Partido Libertario en Cuba.

Pamela dice que concuerda con algunas ideas de "Agustín" y con otras no tanto. Contar con el "plus" de ser mujer la habilita a plantear ciertos temas e ir a fondo, a diferencia del referente joven de la alt right argentina, quien "se tiene que frenar, aunque no lo parezca": "Él rescata la primera ola del feminismo. Yo no. Es una discrepancia que tenemos. Yo voy a profundizar mucho más. Por ejemplo, él plantea que el capitalismo liberó a la mujer y yo planteo que la mujer nunca fue sometida". Disentir es un acto que le permite posicionarse, primero como lectora crítica y luego como columnista y escritora con ideas propias. Se sabe "más anarquista" que el presidente de la Fundación Libre porque adhiere al "paleolibertarismo", una corriente del libertarismo desarrollada por los pensadores Murray Rothbard y Lew Rockwell, que combina valores culturales conservadores con una oposición a la intervención y a la existencia del Estado. Los liberales clásicos con los que comulga Laje, en cambio, postulan un Estado mínimo, con normas de justicia y seguridad. "Eso - dice- va a cambiar necesariamente tu concepción del feminismo y del voto. Si quieres que el Estado esté fuera de tu vida no rescatas nada de eso".

Aunque ser mujer y hablar de feminismo le parece un cliché, tiene contemplado escribir un libro sobre la temática para el sello Unión. "Ellos me pidieron a mí", aclara. Aún no cuenta con los bocetos pero quiere demostrar que el feminismo es funcional al socialismo. En esa dirección, imagina un título que a primera vista despiste y pueda serle atractivo a un público de izquierda -del estilo "feminismo y socialismo, dos caminos entrelazados"-, de modo que el lector, a medida que se adentre en las páginas, descubra un contenido sustancialmente distinto al esperado.

Para Pamela es prioritario alcanzar una síntesis entre las diversas tendencias de derecha:

Un amigo me dijo el otro día... yo pensé que iba a decirme que estaba muy conservadora últimamente, pero me dijo: 'vos sos liberal, sos más liberal que los liberales. ‘¿Por qué?’ le pregunté yo. 'Porque vos tolerás a los conservadores'.

La apelación a una ética de la tolerancia entre doctrinas reemerge en varios tramos de la entrevista. Le gustaron las últimas palabras de Márquez en el auditorio de Belgrano referidas a este aspecto y desde entonces las hizo suyas:

Me pareció muy valioso cuando dijo que el nacionalismo vuelque su amor por la patria y la libere del estado, que sea por la nación y no por el Estado. Al conservador que abrace el progreso, y al libertario que valore la vida como primer derecho. Entonces tomar las líneas en común y capacitar al otro en lo que está débil. A mí eso me pareció constructivo (Pamela, 33 años, marzo de 2019). 
Con esa tónica, escribió un ensayo donde ella, libertaria, propone pensar a la familia como "base de la sociedad libre" porque es la mayor garantía de la seguridad social y, sobre todo, porque le quita al Estado su razón de ser.

Pero la amalgama de valores liberales, nacional-católicos y conservadores demanda una serie de flexibilidades y esfuerzos que van más allá de las lecturas, de la pluma y el papel. Impele a asumir comportamientos y prácticas en la vida cotidiana, en una suerte de praxis donde el trabajo y la militancia en las ideas deben revalidarse y retroalimentarse de actividades y compromisos en el llano. Desde el año pasado, cuando se involucró en la campaña "pro-vida" y ganó en exposición pública, comenzó a frecuentar círculos de socialización religiosa a pesar de no tener un pasado ligado a la fe. Una vez al mes recorre hospitales públicos con un grupo de evangelistas, porque ser pro-vida y "solo querer que el chico nazca" es muy fácil: "yo no puedo proclamarme provida si solo me dedico a que no se aborte. Esas son las acusaciones que nos hacen, ique solamente nazca!"

En el imperativo de amoldarse, sugiere que la moral cristiana aporta un marco de valores, un "contenido valórico" que deviene compatible con su filiación libertaria, al promover redes de solidaridad en la esfera privada y disputarle al Estado la hegemonía moral para determinar lo que está bien y lo que está mal. Los miércoles también hace caridad con un movimiento católico, aunque eso no la cohíbe de criticar la aletargada reacción que tuvo la Iglesia para movilizar a sus fieles en la causa "pro-vida". Entre risas, recuerda la vez que logró ingresar a un espacio católico por intermedio de un conocido:

Fue chistoso porque me presentó como "una amiga muy católica" y pensé ‘¿Yo, muy católica?' Ni siquiera me confirmé, ni siquiera sé que responder antes los ritos, o sea, soy católica porque soy bautizada e hice la comunión. ¡Y encima hicieron un video de lo que fue la gesta pro-vida y aparezco yo! (se ríe) (...) ¡Salgo con un rosario y al lado de un fraile! (se ríe). No es que lo reniego, simplemente no soy la representante de... o sea en mi caso no fue mi fe lo que me llevó al movimiento pro-vida sino el movimiento pro-vida lo que me llevó a la fe (Pamela, 33 años, marzo de 2019).

\section{La religión para restaurar, la política para argumentar}

"Ella sabe un montón", nos comenta Joaquín en referencia a Pamela, a la salida del evento en el auditorio de Belgrano. Con 26 años, estudiante de Ingeniería Industrial en la UNSAM y oriundo de la localidad bonaerense de Ballester, Joaquín se ubica en una fase de "investigación primaria" y de "aprendizaje". Desde el inicio, nos advierte que nunca tuvo incorporado el hábito de la lectura pero que quiere empezar. Si bien el ejemplar de Laje y Márquez sobre la "nueva izquierda" aún persevera en la biblioteca de su casa, y promete leerlo pronto, tampoco considera que el libro sea la única opción para aquellos millenials que, como le sucede a él, se inclinan por el formato audiovisual.

Joaquín pertenece a una familia cristiana, donde la música ocupa un lugar preponderante. Su abuelo era evangelista y productor discográfico y su tío es cantante en una banda y un 
pastor de renombre en los espacios de socialización cristiana. Hace unos años forma parte de una banda junto a su primo y unos amigos. Componen música cristiana, no porque se lo hayan propuesto sino porque "les sale así":

Cuando escuchás las canciones no te das cuenta igual, es que no podemos evitar que nuestras letras tengan que ver con eso. Para nosotros no es tipo 'hago una banda y tengo una obligación de escribir sobre Dios y decir que es bueno'. No, es algo que te sale natural. Cuando conocés a Dios, es imposible que no esté involucrado en todos los aspectos de tu vida (Joaquín, 26 años, marzo de 2019).

El hecho de que su papá sea ginecólogo coadyuvó a que la problemática del aborto y la inculcación del respeto a "la vida" estuvieran muy presentes desde chico. Aclara, sin embargo, que originalmente el tema no tenía connotación política alguna. Más bien era la expresión y confirmación de la moral cristiana observada en el seno familiar, sumado a la expertise médica de su padre, que impartía charlas y seminarios desalentando la práctica. De acuerdo a Joaquín, no fue él quien se metió en política, sino que fue la política la que se metió en su vida: "se empezó a aparecer de a poco en mis ámbitos". Primero, por intermedio de su hermano mayor, que además de ser invocado varias veces como el reverso positivo de todo lo que él no es -aplicado, estudioso, lector, líder nato- destaca como precursor en los debates públicos en contra del aborto.

Y segundo, a partir del debate en el Congreso, entre mayo y agosto de 2018. El rito de pasaje que atravesó Mamela en el último año - un tránsito donde su filiación ideológica y adhesión al movimiento "pro-vida" la acercaron a espacios de socialización religiosa- se dio de manera invertida en el caso Joaquín. El debate parlamentario lo instó a pensar estos temas, ya no desde un prisma exclusivamente religioso sino apelando a una lógica que apunta a ser política: "Dios nos dio la vida y la vida es sagrada, porque es una creación de Dios. Y corromperla de cualquier manera está mal. Es re sencillo, o sea, no hay mucha vuelta que darle. Para restaurar y recomponer la religión es una herramienta importante, pero para argumentar me parece que no sirve prácticamente de nada”. Ante esa falta, los referentes que sigue y admira le aportaron herramientas conceptuales para entender el presente político y su ubicación en él, así como para revisitar su pasado desde un "pensamiento crítico":

Yo era totalmente apolítico y de repente empecé a entender en qué punto estaba de la política, porque uno siempre tiene un punto en la política, aunque no quiera. Entonces me di cuenta que, durante toda mi vida en el colegio, en la secundaria, en la facultad en los primeros años, en muchas etapas de mi educación me quisiera tirar para el lado de la izquierda. Un día... ¿ viste cuando juntás cosas para tirar? bueno, yo estaba revisando cosas de la primaria y de repente veo todo los cuadernos y pienso 'guau, ¿qué pasó?' (Joaquín, 26 años, marzo de 2019).

El ingreso en estos espacios de sociabilidad y circulación de ideas supuso para muchos jóvenes un "momento liminal" (Turner, 1969), de transición y quiebre, que exige primero reflexionar y volver conscientes las categorías identificantes previas que organizaban su vi- 
sión del mundo, para luego distanciarse y despojarse de ellas (Badaró, 2009). En el caso de Joaquín, el esfuerzo retrospectivo que hace para desnaturalizar la injerencia de "la izquierda" en su educación, curiosamente, nunca es encauzado para examinar con igual ímpetu el peso de la socialización cristiana en su trayectoria. Esa revisión no pareciera necesaria. Las estructuras morales y los razonamientos en torno a creencias continúan operando en los nuevos espacios de lucha contra la "ideología de género".

Así como la fe conforma un basamento de la espiritualidad religiosa, Joaquín admira a Laje en el terreno propiamente "político" porque "lee muchísimo, cita constantemente a gente que no sabés quién es, ipero le creés! ¡está tan seguro de lo que dice que le creés!”. En estos espacios donde la politización de lo sagrado y la sacralización de la política se anudan e implican de forma singular, este joven seguidor, como tantos otros, se siente cautivado con los referentes de la alt right argentina porque "ponen en palabras lo que uno siente, encuentran las palabras justas para expresar algo que ni siquiera sabés bien qué es".

\section{Conclusiones}

Este artículo, de carácter exploratorio, apuntó a indagar el valor que tiene el libro en espacios de derecha para aquellos lectores que consumen y se vinculan con las obras. No sólo permiten materializar, sistematizar ideas y discursos sociales previamente existentes, sino que además cumplen un rol activo en la proliferación de nuevos vínculos, identidades y sociabilidades políticas. Funcionan, de este modo, como vector e insumo para la construcción y consolidación de culturas y sociabilidades políticas.

Los lectores consideran que los referentes y sus libros sintetizan sentimientos y pensamientos que no sabían cómo expresar, además de valorar el hecho de que aportan "datos". Mientras en los eventos forman fila para que sus autores le incorporen una marca simbólica adicional con su firma, en la vida cotidiana el libro facilita la identificación y el reconocimiento entre pares, así como la oposición y discusión con los adversarios. Como muestra la entrevista a Santiago, los lectores empuñan sus libros con orgullo, certificando con ellos la adhesión a un espacio. Joaquín, en cambio, no es un lector avezado y se inclina por formatos audiovisulaes (videos de Youtube, redes sociales) para consumir las ideas de Laje y Márquez, pero, aun así, intuye que debe leer El libro negro de la nueva izquierda para afirmar su pertenencia.

Asimismo, en un contexto donde el imperativo era consolidar una fuerza capaz de hibridar e incluir a las derechas en plural, estos jóvenes muestran inclinaciones por una vertiente ideológica en particular, sin que ello implique menos apertura hacia las otras doctrinas. El caso de Pamela es elocuente en este aspecto. Los libros y los eventos y espacios que afloraron a partir de ellos le permitieron redescubrir otras tendencias que confluyen dentro de la derecha, y redefinir en nuevos términos su identidad política. Además, la cercanía personal que mantiene con Laje a partir de su pertenencia a la Fundación Libre la llevaron a querer participar de la distribución del capital simbólico que proveen los libros: entiende, de manera menos o más consciente, que para posicionarse en estos espacios es necesario contar con un libro de autoría propia. 
Este trabajo apuntó a contribuir al análisis de la relación entre cultura y política, prestando atención al lugar que ocupa el libro, sus instancias y sus agentes de mediación para la construcción de espacios de sociabilidad donde proliferan y circulan discursos de derecha actual. Para futuras indagaciones se prevé, en primer lugar, avanzar en el conocimiento del circuito editorial de estos libros, analizando las trayectorias de sus editoriales, editores, autores y divulgadores. Y, en segundo lugar, acceder a la voz de los referentes para analizar, entre otros aspectos, qué valor que le otorgan al libro como artefacto de difusión, cómo se inclinan por este formato y qué expectativas y lectores proyectan. Consideramos que, además del estudio de las ideas que los autores difunden, es necesario analizar las instancias materiales que orientan su producción, circulación y recepción.

\section{Notas}

1. En este trabajo utilizamos la categoría de "derecha" como una categoría política nativa en la cual se reconocen los propios agentes que se estudian.

2. Así todo, los comicios electorales de 2019 dejaron una novedad inquietante para el análisis del mapa político argentino: de las cinco fórmulas que en las elecciones PASO superaron el piso de 1,5\% de votos para competir en primera vuelta, dos de ellas lo hicieron en representación de la derecha argentina. La variante más liberal en lo económico estuvo liderada por el economista José Luis Espert, mientras que la versión de cuño conservador, nacionalista y militarista tuvo como candidato al oficial (R) del Ejército y ex combatiente de Malvinas, Juan José Gómez Centurión. Si bien ambos frentes obtuvieron magros resultados (Espert obtuvo un 1.48\%, mientras que Gómez Centurión alcanzó un 1.71), su aparición y "sobrerrepresentación" en las elecciones devela un reverdecimiento de estos sectores.

3. Márquez también publicó El Vietnam argentino. La guerrilla marxista en Tucumán (Edición del autor, 2008); El canalla. La verdadera historia del Che (Edición del autor, 2009); Chávez. De Bolivar al narcoterrorismo (Edición del autor, 2010); El impostor. Evo Morales, de la Pachamama al narco-estado (Contracultura, 2012); El cuentero de Carondelet: Rafael Correa (Contracultura, 2013); Perón, El fetiche de las masas. Biografía del dictador más polémico de Argentina (Unión, 2015) y La máquina de matar. Biografía definitiva del Che (Unión, 2017).

4. Se trata de un think thank liberal cordobés presidido por Agustín Laje. Cuentan con un sitio web y un newsletter, en donde comunican las novedades sobre publicaciones, libros y artículos que sus integrantes realizan. https://fundacionlibre.org.ar/

5. La editorial Unión es de origen español y en los últimos años ha venido incursionando principalmente en la publicación de autores reconocidos como referentes del liberalismo, libertarismo y la escuela austríaca, tanto en Argentina (algunos de sus autores son Ricardo López Murphy, Javier Milei, Diego Giacomini, Ivan Carrino y Agustín Echevarne), como en España (Marcos de la Fuente, Luis Reig, Joaquín Reig, Julio Pascual y Francisco Gómez) y a nivel global (Ludwig von Mises, Friedrich A. Hayek, Murray Rothbard o Bertrand de Jouvenel). Una primera aproximación a esta editorial, a su director editorial y a su rol articulador de la derecha local puede encontrarse en Saferstein y Goldentul (2019). 
6. Justicia y Concordia es una asociación que surgió en 2009. Reúne a abogados y personalidades del derecho que cuestionan e impugnan los juicios por crímenes de lesa humanidad reabiertos en 2006.

7. Sirinelli (1993) entiende a la cultura política como una articulación compleja de elementos que incluye un vocabulario propio, relatos y memorias cristalizadas sobre hechos del pasado así como libros y textos canónicos.

8. Los lenguajes de "odio", en tanto discursos que confrontan con la diversidad y pluralidad como valores de una sociedad, han sido objeto de debates en el ámbito jurídico (donde se discute las posibilidades de su sanción y tipificación como delito) como también en las ciencias de la comunicación (en torno al dilema entre la libertad de expresión y la regulación o la limitación pública de estos discursos),

9. Se utilizaron seudónimos a fin de preservar la identidad de los entrevistados.

\section{Bibliografía}

Abélès, M. 1990. Anthropologie de L'Etat. París: Armand Colin.

Badaró, M. (2009). Militares o ciudadanos. La formación de los oficiales del Ejército Argentino. Buenos Aires: Prometeo.

Besoky, J. L. (2016). La derecha peronista. Prácticas políticas y representaciones (1943-1976), [Tesis de Doctorado]. Facultad de Humanidades y Ciencias de la Educación, Universidad Nacional de La Plata, La Plata.

Bohoslavsky, E. y Lvovich, D. (2009). Elitismo, violencia y degeneración física en los diagnósticos de las derechas argentina y chilena (1880 - 1945). Nuevo Mundo Mundos Nuevos. Disponible en: http://journals.openedition.org/nuevomundo/57777.

Canavese, M. (2015). Los usos de Foucault en Argentina. Recepción y circulación desde los años cincuenta hasta nuestros días. Buenos Aires: Siglo Veintiuno Editores.

Canelo, P. y Castellani, A. (2016). Empresarios en el Estado. Radiografía del gabinete nacional actual [Informe]. Programa de Estudios sobre las Elites Argentinas. Buenos Airea: IDAES-UNSAM.

Deaecto, M. M. y Mollier, J.-Y. (Eds.). (2013). Edição e revolução: Leituras comunistas no Brasil e na França. Minas Gerais: Editora UFMG.

D 'Angelo, J. (2014). Mentirás tus muertos. Falsedades y millones detrás del mito de los los 30.000 desaparecidos. Buenos Aires: El Tatú Ediciones.

Darnton, R. (1993) “La France, ton café fout le camp!": De l'histoire du livre à l'histoire de la communication", Actes de la recherche en sciences sociales 100 (1), pp. 16-26.

Dosse, F. (2007). La marcha de las ideas: Historia de los intelectuales, historia intelectual. Valencia: Universitat de València.

Elman, J. (2018). ¿Quién le teme a Agustín Laje? Revista Anfibia. Disponible en: http:// revistaanfibia.com/cronica/quien-le-teme-a-agustin-laje-2/.

García, L. I. (2009). Encuesta sobre el concepto de Recepción. Políticas de la memoria 8-9, pp. 98-109. 
Gessaghi, V. (2016). La educación de la clase alta argentina: entre la herencia y el mérito. Buenos Aires: Siglo Veintiuno Editores.

Giordano, V. y Soler, L. (2016). “Editoriales, think-tanks y política. La producción y circulación de las ideas de las nuevas derechas en Argentina". Revista Paraguaya de Sociología 47, pp. 35-50.

Giordano, V.; Soler, L. y Saferstein, E. (2017). "Las derechas y sus raros peinados nuevos", Apuntes de Investigación del CECYP 30, pp. 171-191.

Gomes, G.; Bohoslavsky, E. y Broquetas, M. (2018). Juventudes conservadoras en los años sesenta en Argentina, Chile y Uruguay. En Mücke, Ulrich y Kolar, Fabián (eds.). El pensamiento conservador y derechista en América Latina, España y Portugal. Siglos XIX y XX, Madrid y Frankfurt: Iberoamericana-Vervuert.

Grandinetti, J. (2019). "La militancia juvenil del partido Propuesta Republicana (PRO) en los centros de estudiantes universitarios", Revista SAAP 1 (13), pp. 77-106.

Grafton, A. (2007). La historia de las ideas. Preceptos y prácticas, 1950-2000. Prismas 11, pp. 123-148.

Hilb, C. (2013). Usos del pasado. Qué hacemos hoy con los setenta. Buenos Aires: Siglo Veintiuno Editores.

Kessler, G. y Vommaro, G. (2018). "La era de las sensibilidades autoritarias". Revista Anfibia. Disponible en: http://revistaanfibia.com/ensayo/la-era-de-las-sensibilidadesautoritarias/.

Leis, H. (2013). Un testamento de los 70. Terrorismo, politica y verdad en la Argentina. Buenos Aires: Siglo Veintiuno Editores.

Katz. Mc Gee Deutsch, S. (2005). Las derechas. La extrema derecha en la Argentina, el Brasil y Chile, 1890-1939 (2005). Quilmes: UNQ Editorial.

Manfroni, C. y Villarruel, V. (2014). Los otros muertos. Las víctimas civiles del terrorismo guerrillero de los 70. Buenos Aires: Sudamericana.

Morresi, S. (2010). “El liberalismo conservador y la ideología del Proceso de Reorganización Nacional”. Sociohistórica 7, pp. 103-135.

Saferstein, E. y Goldentul, A. (2019) "Los jóvenes lectores de la derecha argentina. Un acercamiento etnográfico a los seguidores de Agustín Laje y Nicolás Márquez", Ponencia presentada en CALAS. Plataforma de Diálogo "Nuevos discursos de odio y sus contradiscursos en América Latina”, Universidad Nacional de San Martín, Buenos Aires, 15-17 de octubre.

Saferstein, E. (2017). "La edición como intervención cultural, comercial y política: bestsellers políticos del director de Random House-Sudamericana en el kirchnerismo", Millcayac. Revista digital de Ciencias Sociales 7 (4), 141-164,

Saferstein, E. (2016). La década publicada. Los best-sellers políticos y sus editores: producción de libros, difusión de temas e intervención pública en el mercado editorial argentino (2003-2015) [Tesis de Doctorado]. Facultad de Ciencias Sociales, Universidad de Buenos Aires, Buenos Aires.

Turner, V. (1969). The Ritual Process: Structure and AntiStructure. New Brunswick: Aldine Transaction.

Semán, P. (2006). "Historia, best sellers y política”. Bajo continuo. Buenos Aires: Gorla. 
Shoshán, N. (2017). El manejo del odio. Nación, afecto y gobernanza de la derecha extrema en Alemania. Ciudad de México: El Colegio de México.

Sirinelli, Jean-Francois (1993) "El retorno de lo político", Historia contemporánea 9, pp. 25-35 Sorá, G. (2019) “¿Desde la izquierda? Orfila Reynal como editor protagonista”. Jornadas Izquierdas y Derechas en el Siglo XX Argentino. Categorías, problemas y abordajes, UNC, septiembre.

Sorá, G. (2018) Editar desde la izquierda en América Latina. Buenos Aires: Siglo Veintiuno editores.

Tarcus, H. (2013). Marx en Argentina. Siglo Veintiuno Editores.

Vázquez, M.; Rocca Rivarola, D. y Cozachcow, A. (2016). "Fotografías de las juventudes militantes en Argentina. Un análisis de los compromisos políticos juveniles en el Movimiento Evita, el Partido Socialista y el PRO entre 2013 y 2015”, Villa María: Universidad Nacional de Villa María.

Vicente, M. (2015). De la refundación al ocaso. Los intelectuales liberal-conservadores ante la última dictadura. La Plata: FaHCE/UNGS.

Vommaro, G. (2017). La larga marcha de Cambiemos: la construcción silenciosa de un proyecto de poder. Buenos Aires: Siglo Veintiuno Editores.

\begin{abstract}
This article addresses the relation between edition and politics from the study of the production, circulation and reception of authors and books circumscribed to the right-wing ideology. Recently, the authors Nicolás Márquez and Agustín Laje, published by the right-wing Unión Editorial, have acquired an unusual visibility, reflected in the circulation and selling of their books and the massiveness of their events and presentations. We hold that the communication circuit that produces and reproduces their discourses place the book an object that, as it spreads, allows the authors to become intellectual, cultural and political leaders with "authority" and creates readers communities. They buy, read and use them as a way to ensure their beliefs, feeling and political opinions. From interviews and public monitoring of these authors we explore the forms of sociability and political subjectivation that these authors and their books enable in a space where rightwing ideas circulate in Argentine today.
\end{abstract}

Keywords: Right-wing - ethnography - intellectuals - edition and politics - political culture - editorials - readers.

Resumo: Este artigo trata da relação entre a edição e a política fundamentada no estudo da produção, circulação e recepção dos autores e livros limitados à ideologia das direitas. Recentemente, os autores Nicolás Márquez e Agustín Laje, publicados pela editora da direita Unión, alcançaram uma visibilidade inusual, refletida na circulação e venda dos seus livros e na massividade do público em seus eventos e apresentações. Argumentamos que o circuito de comunicação que produz e reproduz seus discursos, tem livros como objetos disseminados e permite que seus autores se tornem referências intelectuais, culturais 
e políticas com "autoridade", criando asimm comunidades de leitores. Eles compram os livros, os leem e os usam como sustentação e como forma de garantir a suas crenças, sentimentos e opiniões políticas. A partir das entrevistas feitas e acompanhamento público desses autores, exploramos as formas de sociabilidade e subjetivação política que esses autores e seus livros possibilitam em um espaço para a circulação de idéias das direitas na Argentina atual.

Palavras-chave: Direitas - etnografia - intelectuais - edição e política - cultura política editoriais - leitores.

[Las traducciones de los abstracts fueron supervisadas por el autor de cada artículo] 